\title{
A study of fatigue status in Chinese adolescents in an urban city, Jixi
}

\author{
Ning Zou ${ }^{1}$, Masaru Kubota ${ }^{1 *},{\text { Ayako } \text { Nagai }^{1} \text {, Ri Ji Jin }}^{2}$, Shu Xian Liu ${ }^{2}$ \\ ${ }^{1}$ Department of Human Life and Environment, Nara Women's University, Nara, Japan; \\ *Corresponding Author: masaru kubota@chime.ocn.ne.jp \\ ${ }^{2}$ Department of Pediatrics, Jixi Mining Group Hospital, Jixi, China.
}

Received 22 March 2011; revised 20 April 2011; accepted 27 April 2011.

\begin{abstract}
The aim of the study was to clarify the characteristics of fatigue status in Chinese adolescents. 1018 adolescents (490 males, 528 females) aged 12 or 15 years in Jixi city were enrolled. Between May and September 2009, fatigue status was investigated using a questionnaire devised by ourselves, which consisted of 4 physical and 4 mental fatigue items. These questions were scored from 0 to 3 based on the frequency of an item occurring, given as the average of the past one month, and the fatigue scores were calculated. Lifestyle issues such as daily sleep duration, feeling of refreshment in the morning after wake-up, extracurricular sports activity, and breakfast intake, and a physical examination such as height, weight, and waist circumference were also investigated. Physical and mental fatigue scores were significantly higher in subjects aged 15 yrs old than in those aged 12 years old in both genders. These scores in females were significantly higher than those in males at the age of $\mathbf{1 5}$ years. Multivariate regression analysis showed that total (physical plus mental) fatigue scores were associated with female gender and various lifestyles such as unrefreshed wake-up feeling, poor extracurricular sports activity, and more frequent skipping of breakfast. However, body mass index and waist circumference were not associated with total fatigue scores.
\end{abstract}

Keywords: Adolescent; Chinese; Lifestyle; Mental Fatigue; Physical Fatigue

\section{INTRODUCTION}

At present, fatigue is a common social problem both in adults and in children, especially in developed countries [1]. Among several types of fatigue, chronic fatigue syndrome (CFS), defined by intractable physical and mental fatigue lasting more than 6 months with a number of accompanying symptoms, has been most vigorously investigated $[2,3]$. According to several previous surveys, the prevalence of CFS was estimated to be less than $3.0 \%$ in adults [4-6] and less than $0.5 \%$ in adolescents [7-10]. Recently, increasing attention has been paid to fatigue other than CFS in the community of healthy adolescents and children, because fatigue may sometimes disturb their daily activities [11]. Fatigue is also known to be associated with symptoms of depression or anxiety and a risk factor for the future occurrence of CFS $[12,13]$. The prevalence of persistent fatigue in healthy adolescents has been well investigated in western countries $[8-10,12,13]$, however, the reported prevalence has differed widely among studies due to different study designs. On the other hand, there have been no large-scale cohort studies about the actual conditions of fatigue, as far as we know, in healthy Chinese adolescents. This fact led us to investigate the present fatigue status in healthy Chinese adolescents, especially in relation to their lifestyle.

\section{MATERIALS AND METHODS}

\subsection{Subjects}

This study was carried out in Jixi city from May to September in 2009 using 1018 participants. Jixi is a middle class urban city locating in north China with the population of 2 million (2000 census). Enrolled in the present study were 520 students in the $6^{\text {th }}$ grade of elementary school (12 years) and 498 students in the $3^{\text {rd }}$ grade of junior high school (15 years). There were 490 males and 528 females. Physicians at Jixi Mining Group Hospital performed a physical examination that included height, weight, and waist circumference. Waist circum- 
ference was measured at the navel with the subject at the erect position after relaxed breathing. Body mass index (BMI) was calculated by the formula, weight $(\mathrm{kg}) \div$ height $(\mathrm{m})^{2}$. Physician asked the participants about their fatigue status and lifestyles on average over the past one month. We obtained consent for study participation from all students beforehand to use their data in our study. This project was approved by the ethical and epidemiological committee at Nara Women's University.

\subsection{Questionnaire}

We devised our own questionnaire about the fatigue status of the participants. We examined the reliability and validity of our questionnaire using Japanese adolescents at almost similar age to those in the present study. In that investigation, greater than 7.0 of Crohnbach's $\alpha_{s}$, and the construct validity of 0.85 in comparison with Chalder's scale [14] verified these issues. There were 4 items each on physical and mental fatigue as depicted in the Appendix. Each item was scored from 0 to 3 (0, not at all; 1, a few times per month; 2, a few times per week; 3 , almost every day). The scores obtained by the physicians were then summed to calculate physical and mental fatigue scores separately (range: 0 - 12). Questions about lifestyle were: 1) daily sleep duration, 2) feeling of refreshment in the morning after wake-up (excellent, score 0: fair, score 1: poor, score 2) 3) extracurricular sports activity (daily, score 0: sometimes a week, score 1: rarely, score 2), and 4) breakfast intake (daily, score 0: sometimes a week, score 1: rarely, score 2).

\subsection{Statistics}

Differences in mean physical, mental, and total (physical plus mental fatigue) fatigue scores according to gender and age were examined by Student's t test. The association of total fatigue scores with various lifestyle elements, BMI, and waist circumference was evaluated by multivariate regression analysis. A statistical analysis was made by "StatMate IV" (ATMS, Tokyo, Japan). P values less than 0.05 were considered significant.

\section{RESULTS}

\subsection{Factor Analysis of the Instrument}

In order to determine the factor structures of the questionnaire, we have done a factor analysis using an oblique rotation (Promax method). As indicated in Table 1, two dimensions termed as physical and mental fatigue were extracted. In addition, Crohnbach's $\alpha_{\mathrm{s}}$ were 0.72 , 0.74 and 0.79 for physical, mental, and total fatigue scores, respectively. This fact demonstrates the good internal consistency of our questionnaire. The coefficient of factors after the oblique rotation was 0.752 .

\subsection{Physical Fatigue and Mental Fatigue Scores in Relation to Age and Gender}

Table 2 indicates subject numbers according to age and gender. The mean and 95\% confidence interval (CI) of physical, mental, and total fatigue scores for different ages and gender are also shown in Table 2 . These scores at $15 \mathrm{yrs}$ of age were significantly higher than those at 12 yrs of age in both genders $(p<0.01)$. Female gender showed higher physical $(\mathrm{p}<0.01)$, mental $(\mathrm{p}<0.05)$, and total $(\mathrm{p}<0.01)$ fatigue scores only at 15 yrs of age. Among 8 fatigue items, "to feel a lack of concentration" was chosen most frequently, followed by "to feel often tired" and "to feel like lying down". On the other hand, "to feel anxious about health" was chosen least frequently (Data not shown).

\subsection{Association of Total Fatigue Scores with Demographic Factors, Lifestyle, BMI or Waist Circumference}

We performed multivariate regression analysis to investigate the association between total fatigue scores and demographic factors, lifestyles, BMI or waist circumference. As shown in Table 3, female gender, age, unrefreshed wake-up feeling, poor extracurricular sports activity, and breakfast skipping demonstrated significant association with an increase of the total fatigue score. Although statistically not significant, subjects with shorter daily sleep duration tended to have higher total fatigue scores. BMI and waist circumference did not show any significant association.

\section{DISCUSSION}

In healthy adolescents, persistent fatigue that does not

Table 1. Factor analysis of the fatigue questionnaire used in the present study.

\begin{tabular}{lcc}
\hline \multicolumn{1}{c}{ Items } & \multicolumn{2}{c}{ Factors } \\
\cline { 2 - 3 } & Physical Fatigue & Mental Fatigue \\
\hline 1. Often Tired & 0.606 & 0.086 \\
2. Still Tired after Night's Sleep & 0.544 & 0.095 \\
3. Want to Lie down & 0.523 & 0.072 \\
4. Feel Forceless & 0.451 & 0.159 \\
5. Anxious about the Body & 0.052 & 0.456 \\
6. Lack of Concentration & 0.229 & 0.325 \\
7. Sleepy in the Daytime & 0.251 & 0.301 \\
8. Depressed & 0.107 & 0.431 \\
\hline
\end{tabular}


Table 2. Fatigue scores according to age, gender, and subject numbers.

\begin{tabular}{cccccc}
\hline \multicolumn{1}{c}{ Age } & Gender & Number & Physical Fatigue Score & Mental Fatigue Score & Total Score \\
\hline \multirow{4}{*}{12 years } & Total & 520 & $2.3[2.1-2.5] \dagger$ & $2.1[2.0-2.3]$ & $4.5[4.1-4.8]$ \\
& Male & 227 & $2.3[1.9-2.6]$ & $2.1[1.9-2.4]$ & $4.4[3.9-4.9]$ \\
& Female & 293 & $2.2[1.9-2.4]$ & $2.4[2.1-2.6]$ & $4.5[4.1-4.9]$ \\
\multirow{5}{*}{15 years } & Total & 498 & $3.6[3.3-3.8]$ & $4.0[3.8-4.2]$ & $7.6[7.2-8.0]$ \\
& Male & 263 & $3.3[2.9-3.7]^{* *}$ & $3.8[3.5-4.1]^{*}$ & $7.1[6.5-7.7]^{* *}$ \\
& Female & 235 & $3.8[3.5-4.2]$ & $4.3[4.0-4.6]$ & $8.1[7.6-8.8]$ \\
$12+15$ years & Total & 1018 & $2.9[2.8-3.1]$ & $3.1[2.9-3.2]$ & $6.0[5.7-6.3]$ \\
& Male & 490 & $2.8[2.6-3.1]$ & $3.0[2.8-3.2]$ & $5.8[5.4-6.3]$ \\
& Female & 528 & $3.0[2.8-3.2]$ & $3.1[2.9-3.3]$ & $6.1[5.7-6.5]$ \\
\hline
\end{tabular}

$\dagger$ Mean and $95 \% \mathrm{CI}$ in parentheses are shown; Differences between males and females at each age are: ${ }^{*} \mathrm{p}<0.05, * * \mathrm{p}<0.01$, no marks, not significant.

Table 3. Multivariate analysis between fatigue score and demographic or lifestyle factors.

\begin{tabular}{|c|c|c|c|c|}
\hline & Number & Coefficient & $95 \% \mathrm{CI}$ & $\mathrm{p}$ value \\
\hline Total & 1018 & & & \\
\hline Sex & & 0.89 & $0.38-1.41$ & $<0.001$ \\
\hline Male & $490(48.1)^{*}$ & & & \\
\hline Female & $528(51.9)$ & & & \\
\hline Age & & 0.59 & $0.42-0.77$ & $<0.001$ \\
\hline 12 years & $520(51.1)$ & & & \\
\hline 15 years & $490(48.9)$ & & & \\
\hline Sleep (Hours/Day) & $7.0[7.0-7.2] \dagger$ & -0.25 & $-0.52-0.01$ & 0.066 \\
\hline Refreshing after Sleep & & 2.88 & $2.44-3.32$ & $<0.001$ \\
\hline Excellent & $386(37.9)$ & & & \\
\hline Fair & $570(56.0)$ & & & \\
\hline Poor & $62(6.1)$ & & & \\
\hline Sport Activity & & 0.64 & $0.25-1.03$ & $<0.05$ \\
\hline Daily & $474(46.6)$ & & & \\
\hline Sometimes & $459(45.1)$ & & & \\
\hline Rarely & $85(8.3)$ & & & \\
\hline Breakfast Intake & & 0.88 & $0.45-1.32$ & $<0.05$ \\
\hline Daily & $774(76.0)$ & & & \\
\hline Sometimes & $179(17.6)$ & & & \\
\hline Rarely & $65(6.4)$ & & & \\
\hline BMI & $20.1[19.9-20.3] \dagger$ & 0.04 & $-0.11-0.19$ & 0.58 \\
\hline Waist Circumference $(\mathrm{cm})$ & $68.5[67.8-69.1] \dagger$ & 0.03 & $-0.03-0.08$ & 0.36 \\
\hline
\end{tabular}

*Numbers in parentheses indicate the percentages; $\uparrow$ Mean and $95 \% \mathrm{CI}$ in parentheses are shown.

fulfill the criteria of CFS is an important issue in fatigue research. Previous reports from western countries dealt with this theme mainly by using self-reported questionnaires such as Chalder's scales [14] or the Checklist Individual Strength (CIS) [15]. Considering quite subjective nature of fatigue, a self-reported questionnaire is thought to be the reliable and useful method of collecting activity data from a large population of adolescents [16]. Although there were differences in the definition of persistent fatigue among previous studies from western countries, the following consistencies were found [8-10, 12,13]: 1) persistent fatigue was more common in fe- 
males than in males, 2) the prevalence of persistent fatigue increased with age, 3) persistent fatigue was accompanied by psychological disorders such as depression and anxiety, and 4) the appearance of persistent fatigue was associated with lifestyle. Among lifestyle, unhealthy dietary life and irregular sleep habits have been demonstrated as causative factors of persistent fatigue.

In comparison with western countries, the epidemiological study of fatigue in healthy adolescents in Asian countries is quite scanty. Okamoto et al. investigated the characteristics of fatigue in association with lifestyle in 247 healthy Japanese adolescents and found that the complaints most frequently observed were drowsiness and dullness, followed by difficulty of concentration [17]. Moreover, undesirable eating habits or poor lifestyle, such as staying up late at night, were associated with the degree of fatigue. Recently, it is reported that fatigue is largely affected by physical fitness level but very little by exercise habits in healthy Japanese adolescents aged 15 - 20 years [18]. We have recently reported the fatigue status in 1225 Japanese adolescents aged between 11 and 16 yrs by the questionnaire used in the present study, but the method of data collection was "self-reported" [19]. In this study, the fatigue scores increased significantly with age, but there was no gender difference at any age. Moreover, subjects with higher fatigue scores tended to skip breakfast more frequently, and to have less balanced eating habits or lesser sleep duration, as in the present study. "To feel sleepy in the daytime" was the commonest complaint followed by "to feel often tired". On the other hand, "lack of concentration" was the $5^{\text {th }}$ most common complaint. We are uncertain about the reason for this disparity in findings between Chinese and Japanese adolescents. One possible explanation is that there exist basic differences of daily lifestyle in adolescents between Jixi and Nara cities, although both cities are classified as middle class urban cities in their respective countries.

There are several limitations in the present study. First, we developed our own simple questionnaire for investigating the fatigue status. The advantage of using such a simple questionnaire for both participants and physicians is to shorten the time required for answering. However, this questionnaire makes it difficult to compare our results with those of previous studies. Second, the precise details of the identified lifestyle were not fully clarified. For example, the evaluation of diet life was only about the frequency of skipping breakfast. It would be useful to collect detailed information about nutrient intake through diet. Finally, we did not investigate the rate of school absence. School absence is thought to be apparently a serious outcome of persistent fatigue [11]. De- spite these limitations, we believe that our findings have potential implications, since this is the first study, as far as we know, to examine the fatigue status in healthy Chinese adolescents. Chinese adolescents are exposed to high stress due to the competitive and punitive educational environment in China [20]. Therefore, further collection of fatigue data in other districts such as metropolitan or rural cities is warranted for understanding overall fatigue status in the community of Chinese adolescents. Based on such investigation, a plan of intervening lifestyle in adolescents to minimize fatigue should be considered as a future project.

\section{REFERENCES}

[1] Ranjith, G. (2005) Epidemiology of chronic fatigue syndrome. Occupational Medicine (Oxford), 55, 13-19. doi:10.1093/occmed/kqi012

[2] Fukuda, K., Straus, S.E., Hickie, I., Sharpe, M.C., Dobbins, J.G. and Komaroff, A. (1994) The chronic fatigue syndrome: A comprehensive approach to its definition and study. Annals of Internal Medicine, 121, 953-959.

[3] Reeves, W.C., Lloyd, A., Vernon, S.D., Klimas, N., Jason, L.A., Bleijenberg, G., Evengard, B., White, P.D., Nisenberg, R. and Unger, E.R. (2003) Identification of ambiguities in the 1994 chronic fatigue syndrome research case definition and recommendations for resolution. BMC Health Services Research, 3, 25-31. doi:10.1186/1472-6963-3-25

[4] Jason, L.A., Richman, J.A., Rademaker, A.W., Jordan, K.M., Plioplys, A.V., Taylor, R.R., McCready, W.M., Huang, C.F. and Pliplys, S. (1999) A community-based study of chronic fatigue syndrome. Archives of Internal Medicine, 159, 2129-2137. doi:10.1001/archinte.159.18.2129

[5] Reyes, M., Nisenbaum, R., Hoaglin, D.C., Unger, E.R., Emmons, C., Randall, B., Stewart, J.A., Abbey, S., Jones, J.F., Gantz, N., Minden, S. and Reeves, W.C. (2003) Prevalence and incidence of chronic fatigue syndrome in Wichita, Kansas. Archives of Internal Medicine, 163, 1530-1536. doi:10.1001/archinte.163.13.1530

[6] Reeves, W.C., Jones, J.F., Maloney, E., Heim, C., Hoaglin, D.C., Boneva, R.S., Morrissey, M. and Devlin, R. (2007) Prevalence of chronic fatigue syndrome in metropolitan, urban, and rural Georgia. Population Health Metrics, 5, 5-9. doi:10.1186/1478-7954-5-5

[7] Chalder, T., Goodman, R., Wessely, S., Hotopf, M. and Meltzer, H. (2003) Epidemiology of chronic fatigue syndrome and self reported myalgic encephalomyelitis in 5 15 years old: Cross sectional study. BMJ, 327, 654-655. doi:10.1136/bmj.327.7416.654

[8] Rimes, K.A., Goodman, R., Hotopf, M., Wessely, S., Meltzer, H. and Chalder, T. (2007) Incidence, prognosis, and risk factors for fatigue and chronic fatigue syndrome in adolescents: A prospective community study. Pediatrics, 119, e603-e609. doi:10.1542/peds.2006-2231

[9] Viner, R.M., Clark, C., Taylor, S.J., Bhui, K., Klineberg, E., Head, J., Booy, R. and Stansfeld, S.A. (2008) Longitudinal risk factors for persistent fatigue in adolescents. Archives of Pediatrics \& Adolescent Medicine, 162, 
469-475. doi:10.1001/archpedi.162.5.469

[10] Jones, J.F., Nisenbaum, R., Solomon, L., Reyes, M. and Reeves, W.C. (2004) Chronic fatigue syndrome and other fatiguing illnesses in adolescents: A population-based study. The Journal of Adolescent Health, 35, 34-40.

[11] Bakker, R.J., Putte van de, E.M., Kuis, W. and Sinnema, G. (2009) Risk factors for persistent fatigue with significant school absence in children and adolescents. Pediatrics, 124, e89-e95. doi:10.1542/peds.2008-1260

[12] Wolbeek ter, M., Doornen van, L.J.P., Kavelaars, A. and Heijnen, C.J. (2006) Severe fatigue in adolescents: A common phenomenon? Pediatrics, 117, e1078-e1086.

[13] Wolbeek ter, M., Doornen van, L.J.P., Kavelaars, A. and Heijnen, C.J. (2008) Predictors of persistent and new-onset fatigue in adolescent girls. Pediatrics, 121, e449-e457.

[14] Chalder, T., Berelowitz, G., Pawlikowska, T., Watts, L., Wessely, S., Wright, D. and Wallace, E.P. (1993) Development of a fatigue scale. Journal of Psychosomatic Research, 37, 147-153. doi:10.1016/0022-3999(93)90081-P

[15] Vercoulen, J.H., Alberts, M. and Bleijenberg, G. (1999) The checklist individual strength. Gedragstherapie, 32, 131-136.

\section{APPENDIX}

Please score elements from 0 to 3 in boxes as the average for the past one month. (0: not at all, 1: a few times per month, 2: a few times per week, 3: almost every day)

A. Physical fatigue-related elements

1. ( ) How often do you feel tired?

2. ( ) How often do you feel tired after sleeping at night?

3. ( ) How often do you feel like lying down in the daytime?

4. ( ) How often do you feel forceless?
[16] Kohl, H.W., Fulton, J.E. and Caspersen, C.J. (2000) Assessment of physical activity among children and adolescents: A review and synthesis. Preventive Medicine, 31, S54-S76. doi:10.1006/pmed.1999.0542

[17] Okamoto, M., Tan, F., Suyama, A., Okada, H., Miyamoto, T. and Kishimoto, T. (2000) The characteristics of fatigue symptoms and their association with the lifestyle and the health status in school children. Journal of Epidemiology, 10, 241-248.

[18] Demura, S., Yamada, T., Shimada, S. and Uchiyama, M. (2011) Influence of exercise habits and physical fitness level on subjective fatigue symptoms in adolescent students. Health, 3, 20-25.

[19] Zou, N., Kubota, M., Kuruma, E., Kojima, C. and Nagai, A. (2010) Fatigue status in relation to lifestyle in healthy Japanese adolescents. International Journal of Pediatrics, 2010.

[20] Hesketh, T., Zhen, Y., Lu, L., Dong, Z.X., Jun, Y.X. and Xing, Z.W. (2010) Stress and psychosomatic symptoms in Chinese school children: Cross-sectional survey. Archives of Disease in Childhood, 95, 136-140. doi:10.1136/adc.2009.171660

B. Mental fatigue-related elements

1. ( ) How often do you feel anxious about your health?

2. ( ) How often do you feel a lack of concentration to do something?

3. ( ) How often do you feel sleepy in the daytime?

4. ( ) How often do you feel depressed without any special reasons? 